\title{
Frequency Sampling for Microscopic Analysis of Botanical Compositions
}

MARK K. JOHNSON

\section{Abstract}

There is confusion in the literature as to the underlying basis for quantifying botanical mixtures microhistologically. The relationship between particle density and frequency of occurrence is useful for estimating numbers of individuals contained in a large number of sampling units. Applied studies do not adequately report the mathematical rationale behind estimation procedures. This paper explains why certain sampling and quantification procedures are useful when applied to microscope analysis of herbivore diet samples.

Recently, Havstad and Donart (1978) published a paper discussing certain assumptions of the microhistological technique for diet analysis. They said that acceptance of underlying assumptions was important for utilizing the technique. However, before any method can be utilized correctly, investigators should understand the assumptions. The papers of Sparks and Malechek (1968), Cavender and Hansen (1970), and Havstad and Donart (1978) all explain certain practical aspects of quantifying diets using a microscope technique but none of the papers contains a complete description of the mathematical basis for the sampling procedure. While investigators have described variations of the microhistological technique and reported components of error, no one has yet provided a detailed treatment of the mathematical relationships involved when frequency sampling is employed as the quantification procedure. Presumably this was neglected because the procedure is relatively easy to understand for persons with a great deal of mathematical training. This note is intended as a clarification and is directed towards persons without the background needed for deriving these relationships by themselves.

Sparks and Malechek (1968) validated the frequency sampling method reported by Fracker and Brischle (1944) for use with a microscope technique for identifying plant taxa (Baumgartner and Martin 1939). Their method treated each microscope field as a sampling unit and certain assumptions were made: (1) Microfragments of plants were randomly distributed on microscope slides, (2) Microfragments from different plant taxa were the same average size, (3) Dry weight bulk densities of different plant taxa were the same. Assumptions 1 and 2 are valid since the distribution and average number of fragments per microscope field is controlled in slide making.

The relationship between frequency of occurrence and the number of individuals per observation (particle density) has great value for improvement of sampling efficiency. Application allows the replacement of exhaustive enumeration of individuals with a much quicker determination of presence or absence within quadrats. This results in a large savings of time and effort for a given sample size. Conversely, for a given amount of time and effort, a much larger number of samples can be inspected.

In order to explain the relationship between particle density and frequency of occurrence, we must examine the occupancy of cells by randomly assigned objects. The argument is based on a finite number of plant fragments of any species distributed at random over $\mathrm{k}$ microscope fields. If an individual is randomly located in one of $\mathbf{k}$ microscope fields so that each cell is equally likely to be assigned the object, the probability of occurrence (p) of the object in any specific field is $1 / \mathrm{k}$. The corresponding probability of nonoccurrence is given by $1-1 / \mathrm{k}$. Furthermore, if $\mathrm{n}$ such objects are

\footnotetext{
Author is associate professor, School of Forestry and Wildlife Management, Louisiana State University, Baton Rougc 70803

The author thanks Richard Hansen, George Van Dyne, and David Guynn for initial review of this paper. This work is Mississippi Agr. and Forestry Exp. Sta. Contribution No. 3960
}

independently, randomly assigned, the probability that none occur in the specified field is $(1-1 / k)^{n}$.

Now consider the random variable $x_{i}$, which is an indicator of occupancy of the $i^{\text {th }}$ field: $x_{i}=1$ if field $i$ is occupied and $x_{i}=0$ if field $i$ is not. Then $y=\Sigma x_{i}$ is a random variable specifying the number of occupied fields. The average number of occupied fields is given by the expected value of $y$.

$$
\begin{aligned}
E\{y\} & =\underset{i=1}{E\left\{\sum_{i}^{k}\right\}} \\
& =\sum_{i=1}^{k} E\left\{x_{i}\right\}
\end{aligned}
$$

By definition of expected value

$$
\begin{aligned}
\mathrm{E}\left\{\mathrm{x}_{\mathrm{i}}\right\}=1 \cdot \mathrm{p}\left\{\mathrm{x}_{\mathrm{i}}\right. & =1\}+0 \cdot \mathrm{p}\left\{\mathrm{x}_{\mathrm{i}}=0\right\} \\
& =1-(1-1 / \mathrm{k})^{\mathrm{n}},
\end{aligned}
$$

therefore,

$$
\begin{aligned}
\mathrm{E}\{\mathrm{y}\} & =\sum_{\mathrm{i}=1}^{\mathrm{k}}\left\{1-\left(1-1 / \mathrm{k}^{\mathrm{n}}\right\}\right. \\
& =\mathrm{k}\left\{1-(1-1 / \mathbf{k n})^{\mathrm{n}}\right\} .
\end{aligned}
$$

These relationships hold if objects a re randomly distributed among fields. Since the placement of plant fragments on a microscope slide is under technician control, the assumption of randomness can be met for microhistological studies.

The relationship between frequency and particle density is established by applying the formula lim $(1-1 / k)^{k}($ Mood et al. 1974:531). The form of equation 4 may be rewritten as

$$
\begin{aligned}
\mathrm{E}(\mathrm{y}) & =\mathrm{k}\left\{1-(1-1 / \mathrm{k})^{\mathrm{n}}\right\} \\
& \left.=\mathrm{k}\left\{1-\{1-1 / \mathrm{k})^{\mathrm{k}}\right\}^{\mathrm{n} / \mathrm{k}}\right\} \\
& \simeq \mathrm{k}\left(1-\mathrm{e}^{-\mathrm{n} / \mathrm{k}}\right)
\end{aligned}
$$

for large values of $k$. Let the average frequency of occurrence of objects in fields be defined as $F=E(y / k)=E\left\{1 / k \cdot \Sigma x_{i}\right\}=E\{\vec{x}\}$ Then the following relationship yields:

$$
\begin{aligned}
F & =E \bar{x} \\
& =1-\mathrm{e}^{-n / k} \\
& =1-\mathrm{le}^{-\mathrm{d}} .
\end{aligned}
$$

The value $d=n / k$ is particle density. Equation 12 is the standard form of the frequency-density relationship.

Finally, if $m$ different types of objects are randomly distributed in the fields, each type has a specific frequency-density relationship and the densities may be standardized by $r_{i}={ }^{d} i / \bullet m$ $\sum_{i=1}$

$\mathrm{i}=1, \ldots, \mathrm{m}$, to yield relative densities. For example, we may count the presence or absence of several different taxa in a microscope analysis. Since proper mixing and spreading of microfragments assures randomness and independence of particle distributions, separate estimates for each taxon density may be obtained and relative particle densities calculated.

In practical applications one seeks to estimate the average particle density, which is unknown and not easily estimated. This is done by estimating average frequency of occurrence, which is also unknown but more easily estimable, and then converting frequency to density using relationship 12 . It should be noted that mean frequency of occurrence values $(\tilde{x})$ are in fact random variables subject to sampling variability. It follows that the estimate of $d$ 
is only as good as the estimate of $F(x)$.

The relative precision of the density estimator $\mathrm{d}$ is also dependent on the average frequency (Curtis and Mclntosh 1950). As average frequency increases, relative precision increases up to an optimum. Precision decreases for larger values of $F$, so that the estimator $d$ has extremely large variance for $F \simeq 1$. This result imposes constraints on the maximum particle density which is allowable in microscope studies. Conversely, low particle densities of rare taxa, which result when microscope slides are made to avoid high particle densities for abundant taxa, require intensive sampling to yield precise estimates of these particle densities.

\section{Literature Cited}

Baumgartner, L.L., and A.C. Martin. 1939. Plant histology as an aid in squirrel food-habit studies. J. Wildl. Manage. 3:266-268.

Fracker, S.B., and J.A. Brischle. 1944. Measuring the local distribution of Ribes. Ecology 25:283-303.

Havstad, K.M., and G.B. Donart. 1978. The microhistological technique: Testing two central assumptions in south-central New Mexico. J. Range Manage. 31:469-470.

Mood, A.M., F.A. Graybill, and D.C. Boes. 1974. Introduction to the theory of statistics. McGraw-Hill, New York, Third Ed., 564 p.

Sparks, D.R., and J.C. Malechek. 1968. Estimating percentage dry weight in diets using a microscope technique. J. Range Manage. 21:264-265.

\section{RANGELAND HYDROLOGY}

by Farrel A. Branson, Gerald F. Gifford, Kenneth G. Renard, and Richard F. Hadley

Unique in its emphasis on the hydrology of rangelands, primarily arid and semiarid lands, RANGELAND HYDROLOGY provides a text for one aspect of range management where none has existed before. This expanded Second Edition presents in-depth information for those who must manage rangeland or respond to questions about the impacts of land use practices on hydrology.

Included in the new Second Edition are a chapter on modeling with approaches to predicting the effects of land use, and a chapter on the rapidly developing field of snow pack management.

The 352-pages include 197 illustrations, providing rapid access to an assembly of data found nowhere else and useful in the preparation of environmental impact statements. Extensive bibliographic material with each chapter and a subject matter index add to the useableness of the book.

Range scientists and managers, soil conservationists, hydrologists, agricultural engineers, land reclamation specialists, wildlife managers, graduate and undergraduate students and their professors, as well as all interested in the hydrology of arid lands will find RANGELAND HYDROLOGY a valuable addition to their libraries. (352 pages paper laminated cover $\$ 15.00$ US)

Please send me copy (ies) of The Society For Range Management's Second Edition of RANGELAND HYDROLOGY by Branson et al. at $\$ 15.00$ each.

Bill me (plus postage and handling)

Check enclosed (Kendall/Hunt pays shipping and handling)

Charge my credit account: $\square$ Visa $\square$ Master card

Account No.

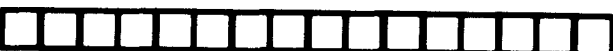

MC Bank \#

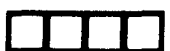

Exp. Date Signature

(required for all charges)

I would like to have one examination copy, free for thirty days. If I decide to keep it, I will be billed at the single copy rate.

Name

Address City, State/ZIP 